\title{
Objeción de conciencia sanitaria en España: naturaleza y ejercicio
}

\section{Health conscientious objection in Spain:} nature and exercise

\section{CARMEN DELIA MEDINA CASTELLANO*}

Resumen: La objeción de conciencia se concibe como el incumplimiento de un deber jurídico, pacífica y moralmente motivado, que procura salvaguardar la propia integridad moral frente a un imperativo heterónomo que se juzga injusto. En general, existe acuerdo social en torno a unos principios de justicia que generan normas compartidas por el grupo. Sin embargo, pueden existir discrepancias entre algunos de los miembros del mismo, que los lleven a optar por la desobediencia a la norma. En este trabajo se pretende reflexionar acerca de la legitimidad social y jurídica de la obligación moral de un individuo de desobedecer o incumplir una norma jurídica incompatible con sus opciones personales, con el objetivo de afirmar dicha facultad y fundamentarla en la existencia de un derecho a la objeción de conciencia. También se quiere poner de manifiesto las dificultades que encuentra en España el ejercicio de la objeción de conciencia en el contexto sanitario.

Palabras clave: objeción de conciencia - obediencia al derecho - derecho humano - derecho fundamental - profesionales sanitarios - objeción de conciencia al aborto

Abstract: Conscientious objection is conceived as the infringement of a legal duty, peacefully and morally motivated, which aims to safeguard the own moral integrity against a heteronomous imperative judged as unfair. Generally, there is social agreement concerning some justice principles that generate group-shared laws. However, there can be disagreement among some of the members of the group, which can lead them to decide to break the law. The aim of this paper is to reflect on the social and juridical legitimacy of an individual's moral obligation to disobey a rule that is incompatible with his or her personal options, in order to assert that faculty and base it on the existence of a conscientious objection right. Also, it seeks to point out the existing difficulties in Spain to exercise the conscientious objection within the healthcare sector.

Keywords: conscientious objection - obedience to the law - human right fundamental right - conscientious objection to the abortion

* Universidad de Las Palmas de Gran Canaria. Cátedra Unesco de Derechos Humanos y Democracia, Las Palmas de Gran Canaria, España. Doctora en Derecho y máster en Bioética. Correo electrónico: cmedina@denf.ulpgc.es 
CONTENIDO: I. INTRODUCCIÓN.- II. PLANTEAMIENTO DEL PROBLEMA.II.1. DELIMITACIÓN CONCEPTUAL.- II.2. EL DEBER DE OBEDIENCIA.- III. LA JUSTIFICACIÓN DE LA DESOBEDIENCIA.- IV. OBLIGACIONES JURÍDICAS SUSCEPTIBLES DE SER OBJETADAS.- V. LA OBJECIÓN DE CONCIENCIA COMO DERECHO FUNDAMENTAL.- V.1. ANÁLISIS JURISPRUDENCIAL.VI. CONSIDERACIONES FINALES.

Vivir es existir absolutamente JOSÉ ORTEGA Y GASSET ${ }^{1}$

\section{INTRODUCCIÓN}

Laobjeción de conciencia se concibe comoel incumplimientode un deber jurídico, pacífica y moralmente motivado, que procura salvaguardar la propia integridad moral frente a un imperativo heterónomo que se juzga injusto $^{2}$. En otras palabras, se trata de la negativa a obedecer una norma jurídica debido a la existencia de otro imperativo en la conciencia contrario al comportamiento pretendido por la norma, pero que en modo alguno supone un empeño de que los demás se adhieran a las creencias o imiten la conducta del objetor.

Es evidente que por alto que sea el acuerdo social en torno a unos principios de justicia, pueden existir discrepancias entre los miembros de un grupo social en materia de concreción de dichos principios, de modo que la objeción de conciencia no requiere invocar la violación de tales principios, precisamente porque se sitúa al margen — pero no en contra- de ese consenso. Quizá son estas dos últimas cuestiones (la inexistencia por parte del desobediente de una voluntad dirigida a conseguir que otros asuman las convicciones en las que fundamenta su negativa y la posible conformidad con un sistema jurídico-político que puede considerar, en general, justo) las que nos acercan al deslinde de la objeción de conciencia de otras formas de desobediencia civil. La primera consiste en no consentir un mandato legislativo más o menos directo, o una orden administrativa ${ }^{3}$, pero no invoca necesariamente principios políticos, aunque puede hacerlo, encontrando su principal justificación en las reglas morales por las que el individuo ha decidido guiar su vida, reglas que no necesariamente han de tener un origen religioso.

En este trabajo se pretende reflexionar acerca de la legitimidad social y jurídica de la obligación moral de un individuo de desobedecer o incumplir una norma jurídica incompatible con sus opciones personales, con el objetivo de afirmar dicha facultad y fundamentarla en la existencia

1 ORTEGa Y GASSET, José. ¿Qué es conocimiento? Madrid: Alianza Editorial, 1992, p. 15.

2 Gascón ABELLÁN, Marina. Obediencia al derecho y objeción de conciencia. Madrid: Centro de Estudios Constitucionales, 1990, p. 217.

3 RAWLS, John. Teoría de la justicia. México D.F.: FCE, 2006, p. 177. 
de un derecho a la objeción de conciencia. También se quiere poner de manifiesto las dificultades que encuentra en España el ejercicio de la objeción de conciencia en el contexto sanitario.

\section{PLANTEAMIENTO DEL PROBLEMA II.1. Delimitación conceptual}

La Declaración Universal de Derechos Humanos de 1948 proclama en el primer párrafo de su artículo 18 lo siguiente: «Toda persona tiene derecho a la libertad de pensamiento, de conciencia y religión». En idéntico sentido se pronuncia el Convenio para la Protección de los Derechos Humanos y de las Libertades Fundamentales de 1950 en su artículo 9.1. También el artículo 18.1 del Pacto Internacional de Derechos Civiles y Políticos de 1966. Otros muchos instrumentos y tratados internacionales recogen estos derechos de libertad de pensamiento, conciencia y religión, pero me gustaría destacar particularmente, por el interés que tiene para el tema objeto de este trabajo, la Carta de Derechos Fundamentales de la Unión Europea, parte del Tratado de Lisboa, cuya ratificación fue aprobada en España por Ley orgánica 1/2008 de 30 de julio.

El interés de la Carta estriba en que incorpora de modo explícito el derecho a la objeción de conciencia. Así, su artículo 10 establece:

1. Toda persona tiene derecho a la libertad de pensamiento, de conciencia y de religión. Este derecho implica la libertad de cambiar de religión o de convicciones, así como la libertad de manifestar su religión o sus convicciones individual o colectivamente, en público o en privado,_a través del culto, la enseñanza, las prácticas y la observancia de los ritos.

2. Se reconoce el derecho a la objeción de conciencia de acuerdo con las leyes nacionales que regulen su ejercicio.

De esta forma, el ordenamiento jurídico comunitario consolida la vinculación entre la objeción de conciencia y las libertades de pensamiento, conciencia y religión. Estas libertades deben ser delimitadas conceptualmente (aun coincidiendo con Salcedo Hernández ${ }^{5}$ en la dificultad de establecer límites «intraspasables» entre ellas), ya que todas tienen como fundamento común la dignidad de la persona y el derecho al libre desarrollo de su personalidad, que pasa por la configuración de un carácter moral sostenido en valores de esa naturaleza en la que se apoyan las elecciones vitales.

4 Boletín Oficial del Estado (en adelante, citado como BOE) 184 de 31 de julio de 2008, con corrección de errores en BOE 98 de 22 de abril de 2009.

5 Salcedo HeRnÁndez, José Ramón. «Libertad de pensamiento, libertad religiosa y libertad de conciencia». Anales de Derecho, 15 (1997), p. 95.

OBJECIÓN DE

CONCIENCIA

SANITARIA

EN ESPAÑA:

NATURALEZA

YEJERCICIO

HEALTH

CONSCIENTIOUS

OBJECTION IN

SPAIN: NATURE

AND EXERCISE 
Son derechos que forman parte de los llamados derechos personales o derechos de autonomía, para diferenciarlos de los derechos personales de crédito o derechos prestacionales. Se trata, como señala Martínez Morán $^{6}$, de un conjunto de derechos que se dirigen a garantizar la conservación de la vida de los sujetos en todas sus dimensiones, pudiendo distinguirse entre aquellos que persiguen primordialmente la integridad física de la persona, y aquellos otros que lo que pretenden es garantizar su integridad moral.

En este sentido, afirma el mismo autor que:

[...] el hombre desde siempre, más o menos conscientemente, ha luchado por su dignidad, tratando de defender no solo su vida biológica sino su significación social como individuo. Su nombre, su honor y su conciencia han sido valorados y defendidos en todas las sociedades como elementos identificados con la vida misma o por lo menos complementarios de ella. El patrimonio moral de estos derechos ha sido defendido, $[\ldots]$ porque todos los aspectos que protegen estos derechos son elementos constitutivos de la personalidad misma, es decir, de la vida integral del individuo $[\ldots]^{7}$.

Son estos derechos de integridad los que permiten a la persona manifestarse en su radical y completa identidad y los que le proyectan a la plena realización.

Siguiendo a Salcedo Hernández, las libertades de pensamiento, religiosa y de conciencia se definen así:

a. La libertad de pensamiento [...] permite a la persona dar una respuesta autónoma a los interrogantes de su vida personal y social; dicho de otro modo, es la concepción que tiene el individuo sobre las cosas, el hombre y la sociedad y de acuerdo con la cual actúa... Es la libertad de pensar y obrar en consecuencia [...].

b. La libertad religiosa [...]se manifiesta en una respuesta personal a la cuestión de la trascendencia del individuo. Implica una toma de postura ante el acto de fe. [En otras palabras], la libertad religiosa tiene por objeto la fe como acto y la fe como contenido de dicho acto, así como la práctica de la religión con toda la variedad de sus manifestaciones, sean de carácter individual o colectivo [...].

c. [Por último, la libertad de conciencia] permite al individuo emitir un dictamen o juicio de la razón práctica acerca de la moralidad de una acción". [Obviamente, si consideramos que la libertad

6 Martínez Morán, Narciso. «Los derechos de libertad». En De CASTRO CID, Benito (coord.). Problemas básicos de filosofía del derecho: desarrollo sistemático. Madrid: Universitas, 1999, pp. 250 y ss.

7 Ibídem, p. 252. 
de conciencia empieza y termina en el propio individuo, no tendría mayor razón de ser. Su sentido se hace real cuando el juicio formado se vincula con la adopción y ejecución de decisiones en razón de los dictados de la propia conciencia $]^{8}$.

Llamazares Fernández unifica algunos aspectos de estas tres libertades bajo el concepto de libertad ideológica, definiéndola como el derecho a «disponer de un espacio de privacidad sustraído a la invasión de la imperatividad del Derecho; a la libre formación de la conciencia; a mantener unas u otras convicciones o creencias, así como a expresarlas o silenciarlas; a comportarse de acuerdo con ellas y a no ser obligado a comportarse en contradicción con ellas» ${ }^{9}$.

La definición resulta de interés porque, de alguna manera, sitúa en un mismo plano de realidad las tres libertades, dejando fuera del concepto aquellos aspectos que están más relacionados con la llamada libertad de culto. Interesa esta idea porque da estructura y soporte a otra que se quiere afirmar, que consiste en la necesidad de desvincular el ejercicio de la objeción de conciencia del hecho religioso, aún cuando en su origen la libertad de conciencia fuera, eminentemente, libertad de religiosa ${ }^{10}$.

La posición que sostengo es que la objeción de conciencia es el resultado de una disconformidad con alguna prescripción concreta del ordenamiento jurídico por razón de las normas morales autoasumidas y que se derivan de la cosmovisión que cada persona tiene, tenga o no fundamento en una determinada creencia religiosa. Hay moralidad también en lo secular, hay desde lo secular un determinado modo de contemplar la propia existencia y el mundo que nos rodea y, en muchas ocasiones se trata de una moralidad compartida, al igual que la que procede de la creencia religiosa de cualquier signo, ya que es el resultante de la propia historicidad y temporalidad de la persona humana. El hombre y la mujer son seres históricos y contextuados, son hijos de su tiempo y de la sociedad en la que viven, con la que comparten no solo un acervo cultural general, sino también moral.

Desde aquí, me parece necesario afirmar la indudable laicidad del derecho a objetar, a pesar de que desde algunos sectores políticos se ha

8 SAlCEDO HERnÁNDEZ, José Ramon. Ob. cit., pp. 96 y ss.

9 Llamazares Fernández, Dionisio \& María Cruz llamazares Calzadilla. Derecho a la libertad de conciencia. Tomo II: Conciencia, identidad personal y solidaridad. Cuarta edición. Madrid: Cívitas, 2011, pp. 21-22.

10 El Edicto de Nantes de 13 de abril de 1598 resulta paradigmático en este sentido. Al respecto, ver Ruíz del Castillo, Carlos. Derecho político. Madrid: Reus, 1939, p. 324; y FernÁNDEZ-MiRANDA CAMPOAMOR, Alfonso. «Estado laico y libertad religiosa». Revista de Estudios Políticos, 6 (1978), pp. 57-80. Señala este autor que «la doctrina luterana del libre examen, con independencia de su valoración general para el católico, lleva en sí una potente carga de respeto y de libertad religiosa que terminará por aflorar con el tiempo. El protestantismo se encontrará en mejores condiciones para conectar con el iusnaturalismo racionalista y aceptar la formulación política de la libertad religiosa como derecho natural de la persona anterior y superior al Estado» (ibídem, p. 60).

OBJECIÓN DE

CONCIENCIA

SANITARIA

EN ESPAÑA:

NATURALEZA

Y EJERCICIO

HEALTH

CONSCIENTIOUS

OBJECTION IN

SPAIN: NATURE

AND EXERCISE 
tratado de negar la existencia de este derecho, vinculándolo para ello al hecho religioso. No hay neutralidad en el individuo; cada uno decide de acuerdo a sus convicciones, que presumimos racionales. Cuestión diferente es que unas personas encuentren su fundamento último en alguna corriente filosófica y otras lo hagan en la fe. La consecuencia para ambas será que deducirán una serie de pautas o normas de comportamiento, que asumirán de modo voluntario y por las que querrán conducir su vida.

Como señala Nogueira Alcalán ${ }^{11}$, la libertad de conciencia protege el proceso racional, reflexivo, la elaboración intelectual del ser humano y su adhesión o no a concepciones valorativas o creencias, sean estas religiosas, filosóficas, ideológicas, políticas o de cualquier otra naturaleza, como asimismo la posibilidad de rechazar aquellas que considera erróneas; proceso que corresponde al fuero interno de la persona que tiene un carácter inviolable, el cual plantea una exigencia de comportarse exteriormente de acuerdo con tales concepciones. Continúa este autor preguntándose por la legitimidad de un Estado que no permitiese a la persona ser ella misma, que no asegurara el contenido básico y esencial del derecho al libre desarrollo de la personalidad.

No obstante, reconociendo el derecho, hay que identificar también sus limites; hay deberes jurídicos que operan necesariamente recortando el alcance de esta facultad de la que hablamos, pero que en ningún caso pueden ser de tal magnitud que desvirtúen o supriman la posibilidad de ejercicio de la libertad de conciencia, y con ella, de la objeción por razón de conciencia.

\section{II.2. El deber de obediencia}

La aceptación de la existencia de un hipotético derecho a la objeción de conciencia requiere la superación del positivismo jurídico riguroso que identifica legalidad y justicia. Es cierto que el ordenamiento jurídico de un Estado democrático liberal debe aspirar a la justicia, pero es obvio que ni el más perfecto de los sistemas es capaz de «realizar» o materializar toda la justicia por medio de la ley. De hecho, aún cuando encarna valores, no es misión de la norma declarar lo que es bueno o malo, sino lo que está permitido o prohibido, aún cuando en las últimas décadas se haya ido instalando en el imaginario colectivo una identificación entre lo legalmente permitido con lo éticamente aceptable.

El primer problema al que nos enfrentamos cuando se aborda la cuestión de la objeción de conciencia es el de la existencia de cierto conflicto de deberes, ya que la necesidad de justificar la objeción surge,

11 NogUeIRA AlCALÁ, Humberto. «La libertad de conciencia, la manifestación de creencias y la libertad de culto en el ordenamiento jurídico chileno". Ius et Praxis, 12, 2 (2006), pp. 13-41, p. 16. 
precisamente, de la aceptación implícita de un deber de obediencia. La cuestión en disputa es, primariamente, si este deber de obediencia a la norma jurídica se prolonga más allá de la propia conciencia, de modo que sea preciso cumplir con un precepto con el que uno está en manifiesto desacuerdo ético ${ }^{12}$. Como señala Gascón Abellán ${ }^{13}$, decir que existe un deber ético de obedecer los imperativos éticos resulta tautológico; en cambio, predicar este mismo deber respecto del Derecho requiere aportar alguna razón para que nos sintamos obligados a cumplir las normas «antes» —aunque no con independencia- de comprobar si coinciden con nuestros imperativos éticos. Es decir, se trata de aportar razones generales que afirmen un deber, también general, de obedecer la norma jurídica.

Existen diversas teorías que justifican la obediencia al derecho. Así, por ejemplo, las doctrinas teleológicas recomiendan la obediencia porque el orden político satisface algún valor ético o es un medio para conseguir fines moralmente buenos, capaces por tanto de generar una obligación o deber de acatamiento. Desde esta perspectiva cabría plantearse si en el marco de estas doctrinas, siempre que se produzca una alejamiento de los fines moralmente buenos que persigue el derecho, sería posible la desobediencia a la norma ilegítima.

Por su parte, las llamadas doctrinas contractualistas tienden a fundamentar la obligación política en el consentimiento de los individuos: de algún modo quieren privar al Derecho de su heteronomía para presentarlo como el fruto de una voluntad autolegisladora de sus destinatarios, en el entendimiento de que, en última instancia, solo una decisión que proceda de la conciencia individual puede ser fuente de un imperativo ético, en este caso de obediencia al derecho ${ }^{14}$. El problema de las doctrinas contractualistas es que su concreción en sociedades multiculturales como las actuales sería sumamente difícil. No sin esfuerzo se consiguen acuerdos en grupos humanos más o menos heterogéneos; mucho más difícil resulta hacerlo en aquellos cuyos individuos asumen sistemas axiológicos muchas veces enfrentados.

Tratando de superar las dificultades que plantean las teorías anteriores, particularmente las tesis contractualistas, la ética comunicativa de Habermas propugna una situación ideal de diálogo que permita a los participantes la consecución de un interés común a todos, a través de una argumentación acorde con las exigencias éticas, de modo que la ética discursiva puede retrotraerse a un principio que reza así: «Solo puedenpretendervalidezlasnormasqueconsiguen(opodríanconseguir)

12 Ver DíAz GaRCíA, Elías. De la maldad estatal y la soberanía popular. Madrid: Debate, 1984, pp. 80 y ss. 13 Ver GASCÓN ABELLÁN, Marina. Ob. cit., p. 121.

14 MARTín SÁnChEZ, Isidoro \& Ricardo GarCía García. "La objeción de conciencia al aborto". En Abellán García-SÁnChez, Fernando \& otros. Libertad de conciencia y salud. Guía de casos prácticos. Granada: Comares, 2008, p. 50.

OBJECIÓN DE

CONCIENCIA

SANITARIA

EN ESPAÑA:

NATURALEZA

YEJERCICIO

HEALTH

CONSCIENTIOUS

OBJECTION IN

SPAIN: NATURE

AND EXERCISE 
la aprobación de todos los afectados, como participantes de un discurso práctico» ${ }^{15}$.

Este dialogo persigue superar la separación existente entre ética y derecho, de modo que cada individuo de la comunidad de dialogantes sería su propio legislador. Sin embargo, como señalan Martín Sánchez y García García ${ }^{16}$, a pesar de su sugestiva formulación, la ética comunicativa de Habermas es susceptible de algunas críticas, especialmente de orden práctico, ya que no parece factible la materialización de una situación ideal de diálogo que permita la formación discursiva de una voluntad general. Además, incluso aunque el consenso universal fuera posible, siempre quedaría una puerta abierta a una posible disidencia por imperativos éticos de la conciencia individual ${ }^{17}$.

Llegados aquí, podemos afirmar que la obligación ética de obediencia al derecho no puede ser absoluta y, por ello, un dictamen de conciencia contrario al deber jurídico, que además no pretende que los demás desoigan la decisión de la mayoría, sino tan solo preservar el ámbito de la propia individualidad, no manifiesta una contradicción entre el deber moral de obedecer los dictámenes de la conciencia en los términos expuestos y un supuesto deber moral de obedecer al derecho, precisamente porque este último resulta limitado y no comprende los supuestos de objeción de conciencia ${ }^{18}$.

Como señala Nogueira Alcalá ${ }^{19}$ la democracia implica el gobierno de la mayoría en el respeto a los derechos de las minorías; en este sentido, los Estados democráticos deben brindar alternativas a los ciudadanos que por razón de conciencia encuentran intolerable la obediencia a un mandato legal concreto, siempre que no genere una consecuencia inaceptable para el bien común, recordando que la apelación a la objeción se produce siempre como extremo último, porque el objetor no pretende mostrar disconformidad con el ordenamiento jurídico en general, ni tampoco, que otros se adhieran a su disconformidad. La objeción es la respuesta a un auténtico conflicto moral. Siempre nace de una conciencia individual cuyo único medio de mantener la integridad personal es la desobediencia a la norma concreta.

\section{LA JUSTIFICACIÓN DE LA DESOBEDIENCIA}

Desde una perspectiva jurídica es posible intentar una justificación de la objeción de conciencia en aquellos ordenamientos que garantizan los derechos fundamentales. Dicha tarea tendría por objeto demostrar que, 
al margen de otros reconocimientos explícitos, la libertad ideológica y religiosa consagrada, por ejemplo, en el artículo 16.1 de la Constitución Española, ofrece cobertura suficiente para acuñar un derecho general - no ilimitado- a desobedecer los mandatos legales por motivos de conciencia y, por tanto, para exonerar de pena a los infractores. De ahí la importancia de deslindar adecuadamente la objeción de conciencia de las otras formas de desobediencia civil, ya que, como se mencionó, no se trata de oponerse al statu quo mediante la desobediencia, sino de no realizar determinada práctica por considerarla altamente vulneradora de la propia moralidad, sin que eso signifique un desacuerdo más amplio con el orden establecido ${ }^{20}$.

Peces-Barba Martínez $z^{21}$ señala que la objeción de conciencia es una desobediencia de naturaleza civil y sectorial que necesita de una juridificación, esto es, una regulación jurídica (convirtiéndose por tanto en una inmunidad o en un derecho subjetivo) y que supone una excepción a la obligación jurídica. Por su parte, Navarro-Valls ${ }^{22}$ define la objeción de conciencia como un conflicto impropio de normas: de una parte, la norma jurídica que impone un deber, fundamentalmente un facere; de otra, la norma moral, que se opone al cumplimiento del mismo. Se rehúsa obedecer un mandato de la autoridad legítima que se entiende radicalmente injusto o delictuoso por entrar en colisión con una norma moral.

Mientras que la desobediencia civil es un «acto público, no violento, consciente y político, contrario a la ley, cometido con el propósito de ocasionar un cambio en la ley o en los programas de gobierno», la objeción de conciencia carece de intencionalidad política, no busca un cambio en las leyes o programas de gobierno, sino que persigue una excepción a un imperativo jurídico concreto y actual, porque este choca con las propias convicciones morales ${ }^{23}$. En palabras de $\mathrm{Raz}^{24}$, la objeción de conciencia es un acto privado hecho para proteger al agente de interferencia de parte de la autoridad pública, mientras que la desobediencia civil es un acto político, un intento, por parte del agente, para cambiar políticas.

Coincido con Gascón Abellán ${ }^{25}$ en que hoy el sistema jurídico interioriza valores, incluye una dosis de moralidad, para que junto a la fuerza reencuentre el consenso, la aceptación individual de la norma. Cuando

20 GASCÓN ABELLÁN, Marina. Ob. cit., p. 91.

21 Peces-Barba Martínez, Gregorio. "Desobediencia civil y objeción de conciencia». Anuario de Derechos Humanos, 5 (1988-1989), p. 168.

22 NAVARRo-VAlLS, Ramón. "La objeción de conciencia al aborto: derecho comparado y derecho español». Anuario de Derecho Eclesiástico del Estado, II (1986), p. 261.

23 SieIRA MUCIENTES, Sara. La objeción de conciencia sanitaria. Madrid: Comillas/Dikinson, 2000, pp. 26 y 27.

24 RAZ, Joseph. La autoridad del derecho. Ensayos sobre derecho y moral. México D.F.: UNAM-Instituto de Investigaciones Jurídicas, 1985, p. 339.

25 GASCÓN ABELLÁN, Marina. Ob. cit., p. 93.

OBJECIÓN DE CONCIENCIA

SANITARIA

EN ESPAÑA:

NATURALEZA

Y EJERCICIO

HEALTH

CONSCIENTIOUS

OBJECTION IN

SPAIN: NATURE

AND EXERCISE 
el sistema jurídico descansa en una constitución que, como la española, recoge como valores superiores del ordenamiento jurídico la libertad, la justicia, la igualdad y el pluralismo político (artículo 1.1), el deber de obediencia al derecho no puede responder al mero temor de la sanción, sino que ha de basarse también en consideraciones morales que forman parte del propio ordenamiento jurídico y que, por tanto, constituyen un criterio de validez de las normas.

Todo acto de insumisión a la norma es resultado de una conducta humana consciente y voluntaria que puede ser evaluada desde un punto de vista ético, con independencia de las consecuencias jurídicas que de la misma se deriven. Por ello, afirmada la obligación de obediencia al derecho, es necesario preguntarse hasta qué punto lo jurídico debe dejar una puerta abierta a un hipotético incumplimiento y, siendo así, qué requisitos ha de reunir este para ser valorado positivamente, ya que, en ningún caso, el reconocimiento del derecho a objetar puede abrir la puerta a la anarquía.

Sin embargo, la justificación de la objeción de conciencia no requiere una confrontación con el sistema político-jurídico, ya que el objetor puede, como se ha mencionado, tener plena conformidad con este sistema en general, pero aún así, sufrir un conflicto entre su conciencia y una norma concreta, de modo que la fuerza del ordenamiento jurídico no llega a convencerle de que su deber moral es comportarse como prescribe la norma, cuando estima que su conciencia le exige comportarse justamente de modo contrario.

Como señala Gascón Abellán, no se propugna el imperio de la arbitrariedad individual, sino que:

[...] «se espera un comportamiento razonable por parte de las autoridades y de los ciudadanos, pero, al final, todos han de tomar su propia decisión y no podemos eludir nuestra responsabilidad [...] no se trata de que cada uno haga lo que le plazca, pero en una sociedad democrática se reconoce que cada ciudadano es responsable de su interpretación acerca de los principios de la justicia, y de la conducta que lleva a cabo a la luz de estos principios» ${ }^{26}$.

En los supuestos en que la ley exige de una persona un comportamiento que su conciencia le prohíbe en virtud de las propias creencias, y esta reclama su derecho a objetar, lo que se pide es el respeto a la conciencia individual, descansando la justificación de su conducta en la libertad de conciencia, de modo que el objetor no debe justificar lo acertado o no de los principios, ideas o creencias en los que basa su objeción, ya que estos solo le competen a él. De hecho, el propio artículo 1.1 de la 
Constitución Española apoya esta idea, ya que la libertad —entendida aquí como autonomía - y el pluralismo son valores que proporcionan un fundamento suficiente para que consideremos que el derecho no puede exigir de una persona que haga lo que cree que es moralmente malo. Es así que la objeción de conciencia supone para la sociedad moderna el reconocimiento de que la ley no agota el ideal de la justicia, un indicador privilegiado de la transformación del Estado de Derecho, que progresivamente pasa a ser el Estado de los derechos ${ }^{27}$.

Ahora bien, lo anterior no significa en modo alguno una ausencia total de justificación de la conducta objetora con sede en la libertad de conciencia; al contrario, el objetor debe justificar su conducta en virtud de la bondad o maldad que de ella se deriva para otros. En otras palabras, el sujeto no necesita argumentar lo acertado de las ideas en las que basa su desobediencia; solo debe justificar su conducta, ya que tiene un impacto sobre los otros, que pueden no tener que soportarlo.

\section{OBLIGACIONES JURÍDICAS SUSCEPTIBLES DE SER OBJETADAS}

$\mathrm{Ra}^{28}$ distingue tres categorías de obligaciones jurídicas susceptibles de ser objetadas. En primer lugar, estarían aquellos deberes impuestos en beneficio o interés del propio sujeto obligado y que atienden a consideraciones de tipo perfeccionista o paternalista, comola prescripción de usar casco para conducir motos y la objeción alegada por los sijes que, por razones religiosas, insisten en usar turbante, incompatible con el uso del casco. En estos supuestos, se aboga por una justificación general de la objeción de conciencia, ya que a juicio de este autor no existen motivos sólidos para imponer la conducta ordenada o para castigar la infracción, pues ningún valor sustantivo es puesto en riesgo como consecuencia del incumplimiento, ya que las normas jurídicas que establecen esos deberes violan el principio de autonomía de la persona y restringen la libre elección de pautas morales para conformar la vida del sujeto, sin que esa restricción pueda justificarse sobre la base de que protege la autonomía de otros.

Algunas objeciones pueden ser hechas a esta argumentación. Si bien es cierto que el tipo de deberes jurídicos al que alude tienen un alto componente paternalista, también lo es que algunas de estas obligaciones jurídicas no afectan exclusivamente al sujeto, si consideramos la dimensión comunitaria de la persona. Pensando en el ejemplo citado, la falta de utilización del casco puede conllevar la muerte de la persona o la aparición de lesiones de importancia, que no solo le afectan a él, sino a la estructura 
familiar y a la sociedad en su conjunto que puede sufrir una pérdida. Además, desde un enfoque utilitarista habría que considerar el coste económico de la asistencia médica y de las posibles secuelas. La segunda, es el valor educativo que tiene la norma en cuanto diseña realidades que, con carácter general, mejoran la vida de las personas. No usar el casco representa un modelo negativo para otros usuarios de este tipo de vehículos. Sin embargo, coincidimos con Raz en que la objeción a deberes de esta naturaleza debe ser fácilmente justificable.

Una segunda familia de obligaciones objetables está formada por todas aquellas que protegen intereses de personas identificables y que, por tanto, suelen representar la contrapartida de los derechos subjetivos de tales personas. En opinión de Raz, hay muy pocas probabilidades de justificar este género de objeciones de conciencia que pueden implicar la lesión de la vida, de la libertad o del honor de otras personas y la razón es simple. Ciertamente no parece que el principio de autonomía personal pueda ser alegado cuando la conducta ataca la inviolabilidad o la autonomía de otras personas. Es decir, según nuestro autor, cuando un deber jurídico ha sido establecido para proteger bienes tan valiosos como la vida o la libertad de las personas no parece que la objeción de conciencia puede estar justificada, pues ello supondría dar primacía a la autonomía del objetor sobre la inviolabilidad de los demás individuos.

Sin embargo, esta afirmación debe ser matizada, pues, como señala Gascón Abellán ${ }^{29}$, no basta la mera constatación de que tras la obligación jurídica existe el interés de un tercero; conviene también valorar la importancia del interés protegido y el grado de peligro a que se ve sometido como consecuencia de la infracción jurídica. En otras palabras: siempre que la obligación jurídica vincule a personas determinadas, debe prevalecer la posición del objetor; en primer lugar, cuando su contribución puede ser mínima y fácilmente sustituible; y, en segundo, cuando tal vez el interés protegido por el deber no encierre ningún valor fundamental o resulte de una importancia menor que la libertad de conciencia del objetor.

En este sentido, una de las consideraciones a tener en cuenta para fundamentar un derecho a objetar por razones de conciencia es el grado de daño al que se ven expuestas las terceras personas, grado de daño que llega a desaparecer o a hacerse mínimo cuando existe la posibilidad de que otros sustituyan al objetor en el cumplimiento del deber. Es este claramente el supuesto que se da en el seno de un equipo asistencial en el que el miembro objetor puede ser sustituido por otro de igual competencia profesional. En este caso, su objeción no causa ningún daño a terceros porque el conjunto de sujetos obligados garantiza el 
cumplimiento de la obligación y, por tanto, no parecen existir motivos para limitar el principio de autonomía personal.

Otro tercer grupo de obligaciones objetables se da cuando la persona en cuyo beneficio o interés se ha establecido la obligación acepta voluntariamente su incumplimiento o incluso reclama ese incumplimiento. La eutanasia voluntaria podría ser un ejemplo de lo que planteamos; en ella, el individuo renuncia a la protección de su vida, reclamando, por el contrario, que alguien acabe con ella, o en otro sentido se rechaza el deber de los otros de no atentar contra la propia vida. Según Raz, el consentimiento de la víctima transforma estas obligaciones en paternalistas, análogas a las estudiadas en el grupo primero, y por tanto considera justificada la objeción de conciencia. En suma, parece que el sujeto obligado se presenta en estos casos como la simple mano ejecutora de la conciencia de otra persona, conciencia que resulta ser contraria al deber jurídico establecido en su propio interés o beneficio ${ }^{30}$ - hablaríamos aquí de objeción impropia, ya que no se incumple el deber por vulneración de la propia conciencia, sino por acuerdo con otro-.

En cualquier caso, a la hora de valorar una modalidad de objeción de conciencia es preciso tener en cuenta, primero, si los intereses ajenos que con ella se ven frustrados son lo suficientemente relevantes como para autorizar un sacrificio de la libertad de conciencia; y, segundo, si el incumplimiento del deber jurídico causa un daño fundamental e irreversible o contribuye en una muy pequeña medida a la satisfacción del interés tutelado. Esta cuestión adquiere relevancia a la luz de la ley orgánica 2/2010, de 3 de marzo, de salud sexual y reproductiva y de la interrupción voluntaria del embarazo ${ }^{31}$, especialmente en lo que al supuesto de despenalización del aborto electivo se refiere, como, más adelante comentaré.

En resumen, el principio de autonomía moral suministra una razón fuerte para considerar justificadas, prima facie, las conductas de objeción de conciencia, sin necesidad de valorar el carácter de los principios morales o de justicia en que dicha actitud se base, es decir, para considerar justificada la objeción de conciencia aún cuando se estime sumamente equivocada. Tan solo cabe formular restricciones (que en su caso pueden anular dicha justificación prima facie) en virtud de principios morales equivalentes correspondientes a otras personas, y teniendo en cuenta para ello tres criterios orientadores:

- Primero, que el interés ajeno sea en verdad relevante desde un punto de vista moral, esto es, que comprometa la autonomía, la 
inviolabilidad o la dignidad de otra persona, y que no se cuente con el consentimiento de esta.

- Segundo, que la conducta del objetor cause un daño importante al interés protegido, lo que permite excluir aquellas obligaciones en que la contribución del objetor es mínima o cuyo cumplimiento está encomendado a varios individuos indistintamente.

- Y, tercero, que la conducta previa del objetor no lo sitúe en una posición de especial compromiso libremente asumido en orden al cumplimiento del deber.

\section{LA OBJECIÓN DE CONCIENCIA COMO DERECHO FUNDAMENTAL}

El uso de la expresión derecho fundamental se generalizó a finales del siglo XVIII y comienzos del XIX, cuando los estudiosos del Derecho Público de Alemania e Italia comenzaron a utilizarla, razón por la cual parece inevitable considerarla una etiqueta vinculada a la función de designar los derechos reconocidos a los ciudadanos en las constituciones y leyes fundamentales. Sin embargo, este uso se ha ido desdibujando paulatinamente, de modo que ha pasado a designar aquellos derechos que, por su importancia y radicalidad son básicos, es decir, fundamentales, en la vida de todo hombre y toda mujer. De este modo, la expresión derechos fundamentales puede indicar, además de un derecho fundamental en sentido propio, otro más evolucionado e impropio que hace referencia a los derechos básicos que tienen todas las personas por exigencias de la propia dignidad personal que les es naturalmente inherente ${ }^{32}$

Aun cuando coincidimos con la mayor parte de la doctrina que considera impropio este uso para designar lo que en realidad deben ser llamados derechos humanos, nos permitimos en este trabajo la licencia de usar esta expresión con su significado impropio, e iniciar a partir de ella la valoración de la objeción de conciencia como un derecho fundamental.

Como derecho humano entendemos el conjunto de facultades o poderes que le corresponden a cada uno de los miembros de la especie humana en razón de su propia humanidad, no designando, por tanto, a los derechos que cada uno tiene en virtud de la peculiar relación establecida en un determinado ordenamiento jurídico estatal o supraestatal, sino aquellos otros que todos los individuos tienen, con independencia de que les hayan sido reconocidos o no por los respectivos ordenamientos jurídicos históricos ${ }^{33}$. 
Es decir, cuando se está hablando de derechos fundamentales como derechos humanos, se está resaltando que se hace referencia a unos derechos cuyo reconocimiento y protección no puede depender de la arbitraria decisión del gobernante de turno. Desde esta perspectiva, afirmamos que la objeción de conciencia es un derecho fundamental.

La conciencia puede definirse como el dictamen de lo que moralmente puede hacerse u omitirse en una situación concreta. No coinciden los dictados de la conciencia con las leyes morales, pues se trata de juicios personales sobre la moralidad de la acción singular y concreta, que va a realizarse, se está realizando o se ha realizado ${ }^{34}$. En términos filosóficos, la conciencia es la facultad de decidir y hacerse sujeto, es decir, actor de los propios actos, y responsable de las consecuencias que de ellos se siguen, según la percepción del bien y del mal.

Es a esta, a su propia conciencia, a la que se enfrenta el profesional sanitario en el momento de tomar una decisión problemática, que se convierte en tal precisamente por las implicaciones que tiene para su conciencia, ya que si no estuviera permitida por la ley, se trataría de una conducta ilegal, y si lo que se viera afectada fuera la norma moral, calificaríamos la acción como inmoral. El profesional se enfrenta a su conciencia porque, aunque las normas jurídicas y morales vigentes en el grupo social al que pertenece le permiten desplegar la conducta que cuestiona, su conciencia moral, fundada en sus creencias, convicciones y en los valores que de estas se desprenden, le señalan esa conducta, cuando menos, como cuestionable.

$\mathrm{Si}$, finalmente, sigue los dictados de su conciencia, esta le puede llevar a la desobediencia civil —si no existe una adecuada regulación del ejercicio de la objeción de conciencia- y a la autoexclusión de la moralidad predominante. A pesar de ello, desde la consideración de su derecho humano a objetar, su conducta, adecuadamente fundamentada y con salvaguarda de intereses o valores superiores de terceros, es legítima desde el punto de vista ético, aun cuando no sea legal.

Ahora bien, cabría plantearse si es posible afirmar la existencia de un derecho fundamental, ahora sí en sentido propio, a la objeción de conciencia. Como señala Peces-Barba Martínez ${ }^{35}$, cuando hablamos de derechos fundamentales estamos refiriéndonos, al mismo tiempo a una pretensión moral justificada y a su recepción en el derecho positivo. La justificación de la pretensión moral en que consisten los derechos se produce sobre rasgos importantes derivados de la idea de dignidad humana, necesarios para el desarrollo integral del ser humano. 
La recepción en el derecho positivo es la condición para que pueda realizar eficazmente su finalidad.

Como antes se señaló, el primer aspecto del carácter fundamental de un derecho está presente en la objeción de conciencia, pero, iqué sucede con su recepción en el derecho positivo español? Como sabemos, la única mención constitucional a la objeción de conciencia se encuentra en el artículo 30.2 de nuestra Carta Magna, fuera, por tanto de la Sección 1 a del Capítulo II relativa a los derechos fundamentales y las libertades públicas. Además, esta mención lo es solo de la objeción de conciencia a la realización del servicio militar obligatorio.

\section{V.1. Análisis jurisprudencial}

Podría concluir aquí mi pregunta, afirmando que no existe un derecho fundamental, y ni siquiera constitucional a la objeción de conciencia en el ámbito sanitario, pero, como también es conocido, el intérprete constitucional aceptó la existencia de este derecho en las sentencias sobre la materia anteriores al año 1987. En este sentido resultó paradigmática la sentencia 53/85 en la que el Tribunal Constitucional declara que «la objeción de conciencia forma parte del contenido esencial del derecho a la libertad ideológica y religiosa reconocido en el artículo 16.1 de la Constitución y, como ha indicado este Tribunal en diversas ocasiones, la Constitución es directamente aplicable, especialmente en materia de derechos fundamentales». De esta manera, el Alto Tribunal parece afirmar la existencia de un derecho general a la objeción de conciencia, dando además respaldo a una modalidad de objeción (objeción al aborto) que no aparece expresamente recogida en el texto constitucional.

Sin embargo, las sentencias 160 y 161 de 1987 niegan la existencia de un derecho general a la objeción de conciencia. La pregunta es qué decisión adoptará el Tribunal Constitucional ante futuros recursos de amparo en los que el infractor de un deber jurídico alegue una modalidad diferente a la del servicio militar, tal y como ocurre con la objeción de conciencia sanitaria.

Dar una respuesta concreta a esta cuestión no es tarea fácil, y dada la tendencia seguida por tribunales inferiores, no es posible aventurar si tal vez estas sentencias de 1987 constituyan la excepción a la regla del reconocimiento de un derecho a la objeción de conciencia general como parte del derecho fundamental a la libertad ideológica y religiosa, o, por el contrario, constituyan un punto de inflexión jurisprudencial que no permita el reconocimiento general de dicho derecho. Sirvan de muestra las dos sentencias que seguidamente se citan:

- La primera, sentencia de la sección $4^{\text {a }}$ de la Sala de lo Contencioso-Administrativo de 23 de enero de 1998, recaída 
sobre el recurso al RD 2409/1986, de 21 de noviembre sobre acreditación de centros sanitarios y dictámenes preceptivos para la práctica legal de la interrupción voluntaria del embarazo, en el que la Sala declara que, «en todo caso, tal exención [de cumplimiento del deber jurídico] constituiría, como ha señalado el Tribunal Constitucional en la Sentencia 53/1985 (F. 14) y esta misma Sala (STS 16 enero 1998), una indudable facultad de enfermeros y médicos que formaría parte del contenido del derecho fundamental a la libertad ideológica y religiosa reconocido en el artículo 16.1 CE, directamente aplicable, por tanto, y cuya existencia y ejercicio no está condicionado por la regulación en el Real Decreto».

- En segundo lugar, la sentencia 1877/2009 del mismo tribunal en la que se niega la existencia de un derecho general a la objeción de conciencia, si bien se ratifica la existencia de un derecho a la objeción de conciencia en materia de interrupción del embarazo, con sede en la sentencia del Tribunal Constitucional 53/85. Así, declara la citada sentencia que además de recordar que el único supuesto en el que la Constitución contempla la objeción de conciencia frente a la exigencia del cumplimiento de un deber público es el previsto en su artículo 30.2, hemos de reiterar que la doctrina del Tribunal Constitucional solamente ha admitido, fuera de ese caso, el derecho a objetar por motivos de conciencia del personal sanitario que ha de intervenir en la práctica del aborto en las modalidades en que fue despenalizado.

Para sostener que, más allá de los específicos supuestos expresamente contemplados por la Constitución, de esta surge un derecho a la objeción de conciencia de alcance general, que no podría ser ignorado por el legislador, suele invocarse - como se ha hecho en el caso ahora examinado- el artículo 16 de la Constitución. La idea básica de quienes sostienen esta postura es que la libertad religiosa e ideológica garantiza no solo el derecho a tener o no tener las creencias que cada uno estime convenientes, sino también el derecho a comportarse en todas las circunstancias de la vida con arreglo a las propias creencias. Pero esta es una idea muy problemática, al menos por dos órdenes de razones [....]. En contraposición a la dudosa existencia en la Constitución de un derecho a comportarse en todas las circunstancias con arreglo a las propias creencias, se alza el mandato inequívoco y, desde luego, de alcance general de su artículo 9.1: «Los ciudadanos y los poderes públicos están sujetos a la Constitución y al resto del ordenamiento jurídico». Este es un mandato incondicionado de obediencia al Derecho. [...] el reconocimiento de un derecho 
a la objeción de conciencia de alcance general a partir del artículo 16 , equivaldría en la práctica a que la eficacia de las normas jurídicas dependiera de su conformidad con cada conciencia individual, lo que supondría socavar los fundamentos mismos del Estado democrático de Derecho.

Una vez sentado que el artículo 16 de la Constitución no permite afirmar un derecho a la objeción de conciencia de alcance general, es preciso verificar si podría encontrar fundamento en la jurisprudencia o en algún instrumento internacional.

Comenzando por los precedentes jurisprudenciales, la verdad es que distan de ser nítidos y lineales. Es indiscutible que la Sentencia del Tribunal Constitucional 53/1985, relativa a la despenalización del aborto en ciertas circunstancias, afirma que el personal sanitario puede oponer razones de conciencia para abstenerse de participar en intervenciones dirigidas a la interrupción del embarazo. Pero a partir de aquí sería muy difícil extraer un principio general por constituir claramente un supuesto límite.

Más clara, como precedente en materia de objeción de conciencia, es la Sentencia del Tribunal Constitucional 154/2002 relativa a la condena penal de unos padres que, a causa de sus creencias religiosas, no autorizaron una transfusión sanguínea para su hijo menor, que luego falleció. Ciertamente, el Tribunal Constitucional consideró que dicha condena penal supuso una violación de la libertad religiosa de los padres; lo que, al menos implícitamente, implica admitir que la libertad religiosa puede tener algún reflejo en el modo de comportarse. Pero tampoco sería fácil extraer de aquí un principio general, por varios motivos: se trata de una sentencia atinente a cuestiones específicamente religiosas, no morales en general; se trata de una sentencia aislada; y se trata, sobre todo, de una sentencia muy ligada a las innegables exigencias de justicia material del caso concreto.

Termina diciendo la referida sentencia que la jurisprudencia constitucional española, en suma, no ofrece base para afirmar la existencia de un derecho a la objeción de conciencia de alcance general, añadiendo que por lo que se refiere a instrumentos internacionales que satisfagan las características exigidas por el artículo 10.2 de la Constitución para ser guía de la interpretación en materia de derechos fundamentales, el único que puede traerse a colación es el ya referido al inicio artículo 10.2 de la Carta de Derechos Fundamentales de la Unión Europea, que dispone lo siguiente: «Se reconoce el derecho a la objeción de conciencia de acuerdo con las leyes nacionales que regulen su ejercicio». 
Es verdad que este precepto no limita el derecho a la objeción de conciencia a un ámbito material determinado. Y es probable que, tras la mención específica a la Carta en el artículo 2 de la Ley Orgánica 1/2008, por la que se autoriza la ratificación del Tratado de Lisboa, aquella debe ya ser utilizada como canon interpretativo. Ahora bien, el artículo 10.2 de la Carta, además, requiere expresamente una interpositio legislatoris para desplegar sus efectos, por lo que no admite un derecho a la objeción de conciencia en ausencia de ley que lo regule.

Siendo así, parece razonable concluir que, en el contexto sanitario, solo sería posible alegar razones de conciencia en los supuestos de aborto, porque la ley orgánica 2/2010, de 3 de marzo, de salud sexual y reproductiva y de interrupción voluntaria del embarazo, establece lo siguiente en su artículo 19.2:

Los profesionales sanitarios directamente implicados en la interrupción voluntaria del embarazo tendrán el derecho de ejercer la objeción de conciencia sin que el acceso y la calidad asistencial de la prestación puedan resultar menoscabadas por el ejercicio de la objeción de conciencia. El rechazo o la negativa a realizar la intervención de interrupción del embarazo por razones de conciencia es una decisión siempre individual del personal sanitario directamente implicado en la realización de la interrupción voluntaria del embarazo, que debe manifestarse anticipadamente y por escrito. En todo caso los profesionales sanitarios dispensarán tratamiento y atención médica adecuados a las mujeres que lo precisen antes y después de haberse sometido a una intervención de interrupción del embarazo.

Algunos rasgos definitorios del ejercicio de la objeción de conciencia en materia de aborto, y sin ánimo de hacer un examen exhaustivo, serían los siguientes:

- Requiere una declaración anticipada y por escrito, o lo que es lo mismo, no se admite la objeción sobrevenida. Esta fórmula constituye una indudable limitación para el ejercicio de la objeción de conciencia, porque el objetor no lo tiene que ser, necesariamente, a todos los supuestos de aborto, de modo que se puede discrepar, por ejemplo, del aborto libre sin indicación médica, pero no de los otros supuestos que la ley contempla ${ }^{36}$,

36 La ley orgánica 2/2010 recoge como supuestos despenalizados de aborto los siguientes: 1. Interrupción voluntaria a petición de la mujer dentro de las primeras catorce semanas; 2 . Interrupción por alguna de las siguientes causas médicas: a) grave riesgo para la vida o la salud de la embarazada; b) riesgo de anomalías en el feto; c) detección de anomalías fetales incompatibles con la vida; d) detección en el feto de una enfermedad extremadamente grave o incurable en el momento del diagnóstico. La diferencia entre los tres últimos supuestos es que el primero - riesgo de anomalías fetales - se puede practicar hasta la semana 22 de gestación, como máximo, mientras que los dos últimos supuestos carecen de plazo, pudiéndose practicar en cualquier momento de la gestación.

OBJECIÓN DE CONCIENCIA

SANITARIA

EN ESPAÑA:

NATURALEZA

Y EJERCICIO

HEALTH

CONSCIENTIOUS

OBJECTION IN

SPAIN: NATURE

AND EXERCISE 
y no parece que se permita el profesional matizar su declaración de objeción.

- Solo pueden alegar razones de conciencia aquellos que participen directamente en la práctica del aborto, lo que parece adecuado si tenemos en cuenta que, por ejemplo, el médico que hace la analítica preoperatoria no realiza actos sustancialmente diferentes a los que se requieren para otro tipo de intervención. Sin embargo, cabría plantearse qué se quiere decir con participación directa: ¿incluye a las enfermeras que cooperan con el ginecólogo que practica el aborto, así como al médico anestesista o al personal sanitario que dispone el quirófano para su uso? La cuestión no parece clara y será finalmente la jurisprudencia la que responda esta cuestión.

- Por último, la ley establece que los objetores deben dispensar atención antes y después de la interrupción voluntaria del embarazo. Eso implica que se les exige que participen en todos los actos previos (como, por ejemplo, facilitar información acerca del aborto), así como en la asistencia posterior. La cuestión es si a alguien que ha objetado razones de conciencia para no participar en el aborto se le puede exigir legítimamente que participe en todos los actos preparatorios.

Otro posible ámbito donde se podrían alegar razones de conciencia es en el de las voluntades anticipadas. En España, la ley 14/2002 de 14 de noviembre, reguladora básica de la autonomía del paciente y de derechos y obligaciones en materia de documentación clínica ${ }^{37}$, reconoce el derecho de los pacientes mayores de edad a emitir anticipadamente su voluntad con respecto a los cuidados, tratamiento, destino de sus órganos, etc., voluntad que desea que se ejecute cuando ya no pueda decidir por sí mismo (artículo 11). El desarrollo que esta norma ha tenido en las diferentes Comunidades Autónomas ha sido diverso, y algunas de ellas han previsto la posibilidad de que el profesional pueda alegar razones de conciencia para no llevar a cabo las disposiciones del paciente. El problema que aquí se plantea es el de la validez regulatoria de esas normas autonómicas en materia de objeción de conciencia, ya que, si bien no es un derecho fundamental, sí es posible decir que se trata de un derecho constitucional, vinculado al artículo 16 de la Constitución española, de modo que, aunque no requiera de ley orgánica para su desarrollo, no parece que sea razonable aceptar que el ejercicio del derecho a la objeción de conciencia dependa de la Comunidad en la que se resida. 
Por todo lo dicho, sería más que deseable que, sin mucha demora, se proceda a la regulación legal del ejercicio de la objeción de conciencia estableciendo, de modo más o menos flexible, los ámbitos, supuestos y requisitos en que puede ser ejercida.

\section{CONSIDERACIONES FINALES}

Como se ha podido apreciar, aunque no existe en el texto constitucional español una referencia expresa a la objeción de conciencia como derecho fundamental, sí es posible afirmar la existencia este, entendido aquí su carácter fundamental como derecho humano. Por su parte, la jurisprudencia del Tribunal Constitucional ha oscilado entre el reconocimiento de un derecho general a la objeción de conciencia vinculado a las libertades ideológica y religiosa (artículo 16.1), y el rechazo de esta posición bajo el argumento de que el reconocimiento de un derecho general a la objeción de conciencia equivaldría, en la práctica, a una pérdida de eficacia de las normas jurídicas.

A pesar de lo anterior, si parece haber existido acuerdo en materia del reconocimiento del derecho a la objeción de conciencia frente a la interrupción voluntaria del embarazo. Esta cuestión ha quedado, en parte zanjada, con la entrada en vigor de la ley 2/2010 de salud sexual y reproductiva y de interrupción voluntaria del embarazo, que reconoce esta facultad a los profesionales que participan directamente en la práctica de un aborto. Sin embargo, la mencionada ley no resuelve los problemas prácticos que la objeción de conciencia plantea en el contexto sanitario. Algunas cuestiones a las que debería responder una futura ley reguladora del ejercicio de la objeción de conciencia en el contexto sanitario serían las siguientes:

a. ¿Qué actos médicos se pueden objetar? Como acabo de señalar, existe acuerdo en la jurisprudencia y en la doctrina sobre la existencia del derecho a la objeción de conciencia en materia de aborto; sin embargo, no parece existir la misma unanimidad cuando se trata de ampliar este derecho a otros supuestos. Así, en materia de objeción a las voluntades emitidas anticipadamente (instrucciones previas, testamentos vitales, directivas anticipadas, etc.) resulta difícil establecer en qué supuestos cabría plantear la objeción. En España, la eutanasia activa directa está penada por la ley (artículo 149.4 del Código Penal), de modo que las diversas normas que regulan las instrucciones previas, tanto a nivel nacional como autonómico, no contemplan la posibilidad de que un profesional intervenga para acortar la vida de una paciente de modo directo contando con el consentimiento de este. ¿Qué puede solicitar el otorgante de un documento de voluntades anticipadas? Entre las disposiciones que puede contener este 
documento están las relativas al destino de los órganos o del cuerpo después de la muerte, el rechazo a un tratamiento, la solicitud de cuidados paliativos. Realmente, lo que el documento de voluntades anticipadas permite es que la persona pueda anticipar su voluntad para que se haga efectiva en el momento en que no pueda decidir por si mismo. De este modo, la objeción de conciencia en estos supuestos es equivalente a rechazar que un paciente, en pleno uso de sus facultades, decida donar sus órganos cuando haya muerto, o que rechace un tratamiento que no desea, o que se le niegue la posibilidad de recibir cuidados paliativos.

Una situación parecida a la anterior se puede dar en los profesionales que alegan razones de conciencia para no intervenir quirúrgicamente a personas que por razones religiosas se niegan a recibir transfusiones de sangre. De acuerdo a las normas ya mencionadas en el cuerpo de este trabajo, el paciente tiene derecho a aceptar o rechazar un tratamiento, sin que deba dar razones de su negativa, reconociéndosele incluso su derecho a equivocarse. Esto no impide que el profesional sanitario rehúse una determinada opción del paciente si considera que es contraria a las reglas de la buena práctica. Para tratar de clarificar este tipo de situaciones la futura ley debería contemplar lo que podemos llamar objeción de ciencia, es decir, la posibilidad de que el médico rechace una determinada opción del paciente si esta es contraria a una correcta práctica médica. En otras palabras, uno de los límites que debe encontrar el ejercicio de la autonomía del paciente es la lex artis.

b. ¿Quiénes pueden objetar? Con carácter general podrían alegar razones de conciencia todos aquellos profesionales que intervengan de modo directo en la interrupción del embarazo. Por intervención directa hay que entender todo lo que constituyan actos necesarios para que la prestación objetada sea satisfecha. En los supuestos de aborto se consideran actos necesarios todos aquellos que se desarrollan dentro del quirófano, de modo que afectan a todo el personal que interviene en el acto quirúrgico: ginecólogo, enfermeras, auxiliares y anestesistas. También podrían ser susceptibles de objeción los actos previos dirigidos a proporcionar información sobre el aborto, y la razón para ello es que no parece tener mucho sentido pedir a alguien que informe y explique un procedimiento con el que no está de acuerdo. Sin embargo, sería de difícil justificación dejar bajo el amparo del derecho a objetar la negativa a llevar a cabo los actos preparatorios de la intervención, tales como las determinaciones 
analíticas o radiológicas, y la razón para ello es que dichas pruebas tienen un carácter general, es decir, no se dirigen específicamente a preparar esa intervención determinada, sino que son comunes a cualquier tipo de ellas.

c. Otra de las cuestiones que genera cierta polémica es la relativa al procedimiento para objetar, ya que la nueva ley del aborto contempla la creación de un registro de objetores al aborto, cuestión con la que discrepan muchos profesionales. Es evidente que la necesidad de organizar los servicios asistenciales para garantizar la prestación, en este caso, la interrupción del embarazo, obliga a conocer quienes son los profesionales que están disponibles para efectuar dicha intervención. Desde esta perspectiva, podría parecer razonable que el registro lo fuera de los que no tienen motivos de conciencia para no practicar el aborto. Sin embargo, el sentido común nos conduce necesariamente a considerar que la norma general es que la prestación se realice sin ningún tipo de obstáculo por parte del profesional competente, y que es la excepción la que debe ser conocida de modo expreso, de manera que deben ser los que objetan los que den a conocer su situación.

Pero precisamente porque la finalidad es organizativa, la nueva ley debería articular el procedimiento de declaración de la objeción de modo que se afectara lo menos posible el derecho a la intimidad del profesional y, para ello, bastaría con que el profesional comunicara a su superior jerárquico (jefe de servicio, enfermera supervisora, o similares) su voluntad de no participar en la práctica de abortos por razones de conciencia. Un registro general, de carácter público, no parece tener más sentido que el de exponer a la vista al que no quiere obedecer la norma por ser contraria a sus convicciones. En definitiva, se trata de evitar la discriminación que podría producirse al alegar razones de conciencia.

Articular una propuesta normativa que agrade a todos en esta materia no es una cuestión fácil, pero los derechos que están en juego - la libertad de decidir de la mujer y la libertad de conciencia del profesionalrevisten una importancia capital y es por ello que vale la pena hacer un esfuerzo que permita lograr acuerdos que garanticen la convivencia pacífica de ambas pretensiones. 